\title{
Can Machines Communicate? - The Internet of Things and Interoperability of Information
}

\author{
Ben van Lier ${ }^{1}$ \\ ${ }^{1}$ Centric, Gouda, Netherlands \\ Correspondence: Ben van Lier, Centric, P.O. Box 338, 2800 AH Gouda, Netherlands. E-mail: \\ ben.van.lier@centric.eu
}

Received: December 21, 2012 Accepted: March 6, 2013 Online Published: April 11, 2013

doi:10.5539/emr.v2n1p55

URL: http://dx.doi.org/10.5539/emr.v2n1p55

\begin{abstract}
In the years ahead, more and more physical objects will be connected to the Internet. These connections will enable objects to exchange and share information among themselves. This way, slowly but surely, an Internet of Things will develop. In this Internet of Things, objects are not only connected to each other, but also to people. At random communication between objects is also called machine2machine communication. This communication is based on the idea, thought up by Shannon, that communication takes place by means of messages that comprise a measurable combination of signals or information. These messages do not have any meaning or content as long as there is no information source to give meaning to this information. The combination of a Shannon message and the meaning given to it will lead to interoperability of information. Interoperability of information is here analyzed and substantiated on the basis of systems theory and sensemaking. Interoperability of Information makes new combinations possible of communication processes of subjects and objects who in this way, will form a new ecosystem comprising interconnected and intercommunicating subjects and objects.
\end{abstract}

Keywords: internet of things, machine2machine communication, interoperability of information, systems theory, sensemaking

\section{Introduction}

In the years ahead, more and more objects will be connected to the Internet. This way, the existing Internet will slowly but surely develop into an 'Internet of Things'. During their creation, objects are increasingly provided with technological possibilities to intrinsically enable such connection. In addition, objects are provided with technological applications during use that allow them to be connected and identify themselves as objects. Cars, for example, are increasingly giving off signals about their general status, whether they need maintenance or repair of specific parts and where this repair can take place. The moment of repair will be determined by communication between my personal digital agenda and the garage's schedule. Nowadays, car navigation systems can determine the optimum route to my destination. To do this, they receive real-time information about the safest, fastest and cheapest route to be taken, which can be adjusted along the way according to the current situation or my preferences. While driving, I can use my smartphone to communicate by means of speech, text and data, while my car is communicating by means of various sim cards with other objects in the vicinity, which are also connected to traditional or wireless telecom networks. Entertainment in the form of music, film or television in the car is adapted to the preferences of its occupants and presented to us by means of the available networks, irrespective of time and place. In case of an accident, cars will be able to determine whether to give off a signal to emergency services, which will respond on the basis of this signal, find the car, and if necessary assess the circumstances of its occupants. Within the next few years, information about lorry loads will be added to this. Thanks to all these connections, the car will take over an increasing number of tasks from me and it can increasingly independently determine what is or should be the best solution in a specific context, comprising time, place and purpose, by means of communicating with other subjects and objects. In the long term, my car will just transport me to a destination specified by me. Many or all actions that I, the human driver, am presently carrying out quite naturally, such as determining the speed, braking, parking, et cetera, will be carried out by the car itself. Whether we are talking about cars, unmanned aircraft, books, television, cameras, clothing, smartphones, packaging of products or computers - everyday objects will increasingly be able to communicate 
and interact among themselves, thanks to technological applications, and take over tasks and responsibilities from humans. This shift from 'agency' between man and 'machine' will increasingly determine our behaviour and action repertoire as a human, organisation or society, for example as described by Van Lier \& Hardjono (2011). The evolution from the existing Internet to an 'Internet of Things', in which not only subjects but also objects are connected to each other, may, according to Sundmaeker et al., develop into an:

"Internet of Services, provided that technology for context-aware, reliable, embedded, energy-efficient and secure distributed networks of cooperating sensors and actuators, as well as the energy provisions for this technology is made available" (2011:22).

\section{The Internet of Things and Machine2machine Communication}

The evolution of the current Internet, in which people exchange and share information among themselves, into an Internet of Things, in which not only people, but also objects are able to exchange and share information, is fed by the increasing communication possibilities of objects. Communication between objects is also called machine2machine communication. In 1947, Ross Ashby defined a 'machine' as: “a number of parts which interact on one another" (1947:47). According to Ashby, the way in which parts of the machine are connected to each other form the organisation of the machine. He considers the whole of parts and connections in the form of a 'machine' as "some dynamic system i.e. something that may change with time" (p. 1954:13). The system thus identified forms an absolute whole with its environment, says Ashby. According to Ashby, a fundamental characteristic of these machines or systems is that "two or more machines can be coupled to form one machine" (1957:48). The possibilities the machine has to connect within itself and connect this dynamic system as a whole with other machines or dynamic systems "can be thought of as 'selforganising', for it will develop to such degree as its size and complexity allow, some functional structure homologues with an "adapted organism" (1962:121). The international Organisation for Economic Co-operation and Development (OECD) has drawn up a report in which it states that machine2machine communication will become an essential part of our society. For example in the development of intelligent electricity meters, intelligent cities, and intelligent electricity networks. According to the OECD, the explosive growth of machine 2 machine communication is driven by a combination of factors, such as increasingly cheap forms of electronics, use of the Internet protocol together with ubiquitous networks, and the rapid development of cloud-computing allowing, in principle, each human being, as an independently operating person (subject), and object to be equipped with a communication device and connected to each other. The OECD states that this form of communication enables objects: "to communicate status and information, which in turn can be aggregated, enriched and communicated internally or onwards to other units. This in turn allows the use of these data in new and useful ways" (2012:8). According to Sundmaeker et al., this form of communication between objects will grow exponentially during the coming decade: "If we consider not only machine-to-machine communication but communication of all kinds of objects, then the potential number of objects to be connected to the internet will rise to 100,000 billion" (2010:13).

It is the opinion of Hua-Dong Ma (2011) that, on the basis of existing information carriers, such as the Internet and telecommunication networks, a combined network will be created that will not only connect people to each other, but also ordinary physical objects, allowing intelligent new services to be created by random combinations of subjects and objects. Where Hua-Dong Ma is concerned, the Internet of Things has three important new characteristics compared to the existing Internet, i.e.:

- Ordinary, everyday objects are equipped with technological applications that enable the unique identification of these objects;

- The individual and autonomous object is independently connected to a network so that this object can be connected with other autonomous objects;

- By making use of large numbers of autonomous objects and actively involving these in existing or new activities, these activities can be performed more intelligently and new intelligent activities can be developed.

Atzori (2010) agrees that the unique identifiability of objects, which enables connection via standard communication protocols, is a typical element of the Internet of Things. He refers to the concept of spimes as described by Sterling. Sterling defined spimes as: "Manufactured objects whose informational support is so overwhelmingly extensive and rich that they are regarded as material instantiations of an immaterial system. Spimes begin and end as data. They are designed on screens, fabricated by digital means, and precisely tracked through space and time throughout their earthly sojourn" (2005:11).

Although, according to Hua-Dong Ma, the existing Internet can connect devices and applications, it does not yet have the possibility of sensory perception of information. It is his opinion, however, that the Internet of Things 
may make use of the connected autonomous objects to obtain: "the additional sensing layer, which reduces the requirements on the capability of devices, and enables the interconnection among the non-intelligent or weakly-intelligent devices" (2011:920). According to Sundmaeker et al., such an extensive network comprising a diversity of technological applications that are connected to each other and exchange and share information with each other requires both a 'total systems' approach and new models for interaction that go beyond the current desktop metaphor. He believes that the architecture of the Internet of Things should enable a distributed ownership of data, whereby: "entities (and things) can control which information to share with other things and entities subject to authorisation controls; the architecture should also support mechanisms for gathering fragments of distributed information from a variety of sources even when those sources are not known a priori, in order to achieve comprehensive end-to-end traceability as far as is permitted'. (2011:60)

The setting up of connections within the Internet of Things and the exchange and sharing of information between random subjects and objects on the basis of these connections, in order to be able to act, produce and generate with this information, is called interoperability of information by van Lier (2009). According to Badyoppadhyay (2011), the realisation of interoperability of information is a crucial precondition for the further development of the Internet of Things. Concerning this, he states: "the central issues are how to achieve full interoperability between interconnected devices, and how to provide them with a high degree of smartness by enabling their adaptation and autonomous behaviour, while guaranteeing trust, security and privacy of the users and their data". Interoperability of information, according to Badyoppadhyay, should enable the connection of random applications with each other in a heterogeneous environment such as the Internet of Things, within which a diversity of software applications and environments and a myriad of technological applications and contexts are active. This also means that we have to ask ourselves, according to Badyoppadhyay, how much intelligence these interconnected objects should possess: "and in which situations this intelligence is distributed or centralised becomes a key factor of development. As the IQ of the things will grow, the pace of the development and study of the behavioural requirements of these objects will also become more prevalent in order to ensure that these objects can co-exist in seamless and non-hostile environments" (2011:23).

It is Atzori's opinion that the development step from the existing Internet to the Internet of Things should be regarded as an interpretation of the Internet of the future. This future Internet will be fundamentally different to the Internet we are using today, taking into account the changes we have outlined here. To Atzori, it has become clear over the past years that the existing Internet is primarily used for the publication and disclosure of information. He believes that information and the exchange and sharing of it should form a central theme in the development and setting up of systems that operate and communicate within networks. According to Atzori, the focus on the functioning of objects in networks will lead to: "the concept of data-centric networks, which has been investigated only recently. According to such a concept, data and the related queries are self-addressable and self-routable." (2010:2803). Information produced by and from random objects connected in networks such as the Internet of Things will not only result in changes in the environment of the producing system, but will also, at the same time, have a relationship with changes in a receiving system, as was determined earlier by Rosenblueth, Wiener and Bigelow (1943). They describe this relationship as follows: "By output is meant any change produced in the surroundings by the object. By input, conversely, is meant any event external to the object that modifies this object in any manner" (1943:1). According to them, this relationship between input and output resulted in changes in the behaviour of the systems concerned. They based the principle of feedback on this, which they defined as follows: "in a broad sense it may denote that some of the output energy of an apparatus or machine is returned as input" (1943:2). The authors distinguished two forms of feedback: positive and negative feedback. It was especially the latter, the negative feedback, that interested them, because they believed that this form was necessary to generate the desired behaviour of the receiving system: "The feedback is then negative, that is, the signals from the goal are used to restrict outputs which would otherwise go beyond the goal. It is this second meaning of the term feedback that is used here. All purposeful behaviour may be considered to require negative feedback" (1943:2). Also in Wiener's time, cars provided interesting comparison material. In one of his examples, Wiener describes the relationship between steering a car and the mechanism of feedback: "Another interesting variant of feedback systems is found in the way in which we steer a car on an icy road. Our entire conduct of driving depends on a knowledge of the slipperiness of the road surface: that is on a knowledge of the performance characteristics of the car-road system"(1954:133).

\section{What Do Machines Communicate?}

The theoretical roots of the question of the relationship between input and output of machines, in the form of machine2machine communication, are found in the work of Claude Shannon. In the beginning of his article 'A mathematical theory of information', from 1948, Shannon observes that: "The fundamental problem of 
communication is that of reproducing at one point either exactly or approximately a message selected at another point" (1948:1). Like Ashby, Shannon believes that the communication system consists of connected 'machines' that mutually exchange information in the form of 'messages'. Shannon's system, as he describes it in his article, comprises five parts, i.e.:

- An 'information source' producing a 'message' or a series of 'messages' that can be communicated to a receiving terminal. The message may take on a diversity of forms;

- A 'transmitter' of the message, processing the message into a signal that makes the 'message' suitable as a signal to be transmitted across a specific channel;

- A 'connection' used by the transmitter to transmit the signal from transmitter to receiver;

- The 'receiver' who carries out the reverse procedure of the transmitter and transforms the signal and is able to reconstruct the message from the signal received;

- A receiving information source in the form of a subject or object for whom the message is intended.

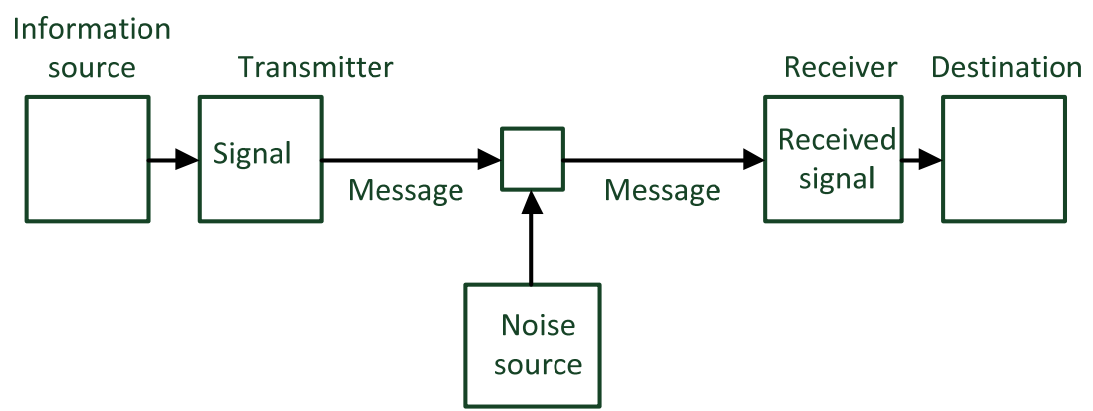

Figure 1. Shannon (1948) communication system

The Shannon communication system shows many similarities to the absolute system described earlier ('machines' connected to each other and their surroundings) by Ashby. The 'message' defined by Shannon can be considered equivalent to the input and/or output as described by Rosenblueth, Wiener and Bigelow. The 'message' as an expression of a combination of signals can therefore be seen as an occasion for change in a receiving system. However, a fundamental question Shannon is confronted with, is: "that the actual message is one selected from a set of possible messages" (1948:1). According to him, a workable communication system should be designed in such a way that it not only enables the selection of the most topical message, but also every possible form of selection from 'messages' to be sent and to be received. Every possible form, because the most topical one is not yet known at the moment of creation of connections within the system. The result of the selection Shannon calls information. He therefore states: "If the number of messages in the set is finite then this number or any monotonic function of this number can be regarded as measure of the information produced when one message is chosen from the set, all choices being equally likely. If the number of messages in the set is finite then this number or any monotonic function of this number can be regarded as a measure of the information produced when one message is chosen from the set, all choices being equally likely" (1948:1).

In order to control the complexity of this problem, Shannon takes a drastic decision and formulates this decision as follows: "Frequently the messages have meaning; that is they refer to or are correlated according to some system with certain physical or conceptual entities. These semantic aspects of communication are irrelevant to the engineering problem" (1948:1). By making this choice, Shannon excludes any form of semantics or context or meaning of the message and limits his theory to technical and measurable signals, which he calls 'binary digits' or, simply, 'bits'. This way, where Shannon is concerned, communication between 'machines' is limited to the technical elements that are necessary to be able to, for example, connect the 'machines' transmitter and receiver by means of measurable 'messages', whereby the subject as an information source is less important. Shannon's choice enabled the boom in telecommunication and ICT over the past couple of decades. It has brought us the Internet as we know it today and the worldwide application and use of smartphones.

\section{Machine2machine Communication and Information}

The limitation applied by Shannon to the definition of machine2machine communication could form an obstacle in the further development towards the Internet of Things, whereby random objects and subjects should learn to 
communicate in a time and place independent way and should be able to form random coalitions in order to realise a specific goal. To enable the latter as an extension of Shannon's theory, we have to go back to his sources, i.e. the concepts of equilibrium and entropy. Ashby (1954) observed that the concepts of 'stability', 'steady state' and 'equilibrium' of a system are associated with a number of definitions that, according to him, all amount to the same thing. He feels that a system is stable when the surroundings of the system are also stable. System and surroundings are balancing each other and as long as nothing changes, nothing will, in fact, happen. According to the opinion of Schrodinger (1944), one of the characteristics of 'living' systems is that they move, do things, and/or exchange elements with their surroundings and that the system will, as long as the circumstances remain the same, continue to do this. When a system is isolated from its surroundings, or if it is placed in a uniform environment, all movements of the system are likely to stop soon because numerous frictions will develop within the system. Slowly but surely, the system will achieve a permanent condition in which observable activities will no longer take place. This latter stage, according to Schrodinger, is also called a thermodynamic equilibrium or a state of maximum entropy. The state of maximum entropy in living organisms can be prevented by means of metabolism, or change or exchange. He therefore states: "everything that is going on in nature means an increase of entropy of the part of the world where it is going on" (1944:71). In other words, the organism will do everything possible to avoid getting into a state of maximum entropy - in the case of an organism: the moment of death. Schrodinger established, therefore, that an organism exists on the basis of negative entropy, i.e. the entropy that keeps him away from maximum entropy. The principle of negative entropy is used by Von Bertalanffy (1950:27) as a basis to determine that every living organism has an essentially hierarchic order of processes that are interconnected in a 'dynamic equilibrium'. Shannon (1948) notes that entropy and the measurability thereof play an important part in the measuring of information, chances and uncertainty. Wiener (1952) continues along this way and observes that: "we deal with automata effectively coupled to the external world, not merely by their energy flow, their metabolism, but also by a flow of impressions of incoming messages, and of the actions of the outgoing messages. The organs by which the impressions are received are the equivalents of the human and animal sense organs" (1948:48).

The question that arises is whether the form of entropy made measurable by Shannon in the form of 'measurable information' is sufficient for any random 'system' to be able to independently act, produce or generate, especially if the phenomenon of information is limited to the mere sending and receiving of messages. Like both Shannon and Wiener have established, their form of entropy is sufficient to be received and sent by 'machines' and to commission these machines to select measurable information from the total number of 'messages' presented. Even if these 'machines' are specifically intended for the sending and receiving of 'messages' and the converting of these 'messages' into processable information. However, Shannon's communication system, as it has already been established above, is not essentially limited to the technical sender and receiver, but also comprises the information sources present behind the technical sender and receiver. Wiener and Shannon also assume that an information source has to be present behind these in order to express or receive the available information. They leave the processing, the interpreting and the giving of meaning to this information to this source that lies behind. In the opinion of Wilkinson (1961), this is the reason that the information theory developed by Shannon is no more than a purely syntactical approach, whereby the subject is exhausted by the formal features of certain conversions into composed units of requested symbols. He believes that with such an operational vision, it is meaningless to distinguish between information and the quantity of information and therefore states: "Since the concept information is a notable nebulous one which adds nothing but confusion to any discourse in which it appears, it is convenient to be able to reject it as a vague, pre-systematic means of saying what we can say precisely with the concept quantity of information" (1961:407). A decade later, Tribus and McIrvine (1971) find that information, as indicated by Shannon, is determined by a "difference between two entropies or uncertainties" (1971:179). They base their observation on that entropy or insecurity is also based on the knowledge of the information source before the 'message' and the entropy or insecurity of the knowledge of the information source after the 'message'. According to Tribus and McIrvine, the information defined by Shannon is only measurable when these information sources are involved, including the measurability of the change in the knowledge of these receivers. That is why they believe that Shannon's definition was an invention aimed at the filling of a specific need, i.e. the provision of a usable method for measuring what is being sent and received through a communication channel. That is why Stonier (1996) argues for a distinction between the concept of information and the concept of the 'message' and therefore he states that: "Information is the raw material which when information-processed may yield a message" (1996:136). Stonier establishes that a 'message' can only be developed once the raw material in the form of information has been created. At the moment the information is received, the receiver has to reprocess this raw material before the 'message' can be given any meaning by the receiver. Stonier (1996) is convinced that a precise distinction has to be made between 
information, the message, and the meaning, because without such a distinction he believes that there can be no theory of communication, also not between machines. Without such a distinction, it will, in fact, become impossible to quantify the information-content of a system. This distinction between raw information and the meaning of information had been observed by Weaver (1949) as well. At the time, he already stated that the phenomenon of communication in relation to Shannon's theory had been given a very broad interpretation indeed. In his opinion, communication also involved procedures of influencing necessary to influence one brain by another by means of communication. Although in the use of the concept of communication, language is often referred to, Weaver feels that communication also refers to music, images and other methods of information transfer. According to Weaver, communication problems have three levels, i.e. 1) technical, 2) semantic and 3) influential. To Weaver, the technical problems of communication primarily involve the accuracy of transmission of the information from sender to receiver. He believes that technical problems are inherent to any form of communication. He therefore states: "Whether by sets of discrete symbols (written speech) or by varying signal (telephonic or radio transmission of voice or music, or by a varying two-dimensional pattern (television)" (1947:11).To Weaver, the semantic problems chiefly involved the interpretation of the meaning in relation to the meaning intended by the sender. According to Weaver, this interpretation already requires a deep and involved connection with the world of the sender: "even when one deals only with the relatively simple problems of communicating through speech" (1947:11). The third and last communication problem distinguished by Weaver is influential. About this, he therefore states: "The problems of influence or effectiveness are concerned with the success with which the meaning conveyed to the receiver leads to the desired conduct on his part" (1947:12).

Despite the major breakthrough realised by Shannon concerning the measurability of information, we can also conclude that the measured part is only a part of the communication between people, between machines, or between combinations of both, as these will develop within the 'Internet of Things'. In that sense, machine2machine communication, as described at the beginning of this paper, may be regarded within the framework of the theory originally defined by Shannon. The measurable information defined by Shannon may be sent, received and converted into processable interpretations and meaning by machines on the basis of 'messages'. However, in order to have people and machines act, produce or generate without any further processing, more is required. The fact that the diffuse use and application of the concept of information is met with increasing criticism, has, among others, been established by McKinney and Yoos (2010). Although the concept of information is widely used in research literature on Information Systems, they believe that it is also a concept of which the specific meaning is rarely determined upon in the context of research. After their study, McKinney and Yoos have determined that: "Virtually all the extant IS literature fails to explicitly specify meaning for the very label that identifies it. This is a vital omission, because without defining what we are talking about, we can hardly know it" (2010:329).

According to them, Information Systems research assumes the term information as obvious, and the discipline does not succeed in identifying and exposing the underlying assumptions of the concept of information, with which further scientific research can be developed. According to McKinney and Yoos, Information Systems research is aimed more at technological progress than progress on the basis of the concept of information. They believe that Information Systems research is continuously rushing forward in order to escape from the fundamental problem of defining information. McKinney and Yoos have determined that: "Information Systems will remain stuck in a pre-paradigmatic state as long as the need for an information taxonomy is ignored" (2010:342).

It can be established that communication between subjects, objects or a combination of both not only comprises the sending and receiving of signals between a 'sender' and a 'receiver' and the translation of the 'message' presented. The process of communication is inextricably connected to the information source and the receiver or sender of information. The combination of information source and the technical object of sender or receiver or a combination of both together form an autonomous system with its own equilibrium. This combined or hybrid system as Van Lier (2009) called it, forms an absolute whole with its surroundings, with which information is exchanged and shared. The exchanging and sharing of information is important to the system in order to be able to survive or to continue to exist within its environment. In this terminology, the exchanging and sharing of information by hybrid systems may be indicated as negative or dynamic entropy. Hence the dynamic entropy of a hybrid system can be equated to the interoperability of information. This way, the technical exchange and sharing of information can be combined with the appointing of meaning to this information by information sources such as subjects or objects. At the same time, interoperability of information may form a connecting factor between scientific disciplines that are, from their different perspectives, involved in the phenomenon of (technical) communication between hybrid systems. 


\section{Interoperability of Information and Meaning}

Within a few decades, particularly the information and communication technology and the resulting applications such as PC, the Internet, and the mobile telephone, have radically changed our society. Communicating, and exchanging and sharing information, by means of technological applications that are connected with each other in networks such as the Internet have become a matter of course to some generations. The number of mobile telephones is increasing across the world and is becoming more and more the most important means of communication. According to Cooper (2005), the postmodern subject is preferably continuously connected with his postmodern object - the mobile telephone - which he takes along wherever he goes. He wants to be in connection with the network everywhere. The postmodern subject becomes individually and collectively disturbed when he is disconnected from his technological object. Cooper explains the need to connect or be connected within a human context as a necessary strategy to be able to present a cohesive world in which non-connected elements are made cohesive as well. Slowly but surely, new technologies and technological applications are becoming an integrated part of our everyday reality. To Clark (2003), the naturalness with which technological applications are adopted in our everyday reality is affected by the extent to which these can be used to achieve our goals. "What matters is that as far our conscious awareness is concerned, the tool itself fades into the background, becoming transparent in skilled use. In this respect the technology becomes, to coin a phrase, 'pseudo-neural'”, (2003:45).

The networks, comprising subjects and objects, that develop in such a natural way, enable connections between subjects on the one hand and objects on the other, as well as between subjects and objects mutually; and this independent of time, place and purpose. The making of connections and, with it, creating possibilities to exchange and share information regardless of purpose, place and time, is leading to an evolution in our perception of reality. This way, reality as we experience it is turning into a more hybrid reality comprising subjects and objects that are interconnected and that exchange and share information among themselves and act, produce or generate on the basis of this information. This possibility of exchanging and sharing information among random subjects and objects is also called the interoperability of information. According to van Lier (2009) the concept of interoperability is a linguistic combination with a multiple meaning. In this context, the 'inter' part stands for the bringing about of relationships between designated or to be designated systems and entities. Operability stands for the producing, performing or influencing on the basis of the information exchanged and shared. The mutual relationship between subjects and objects that is developed in this way, as well as the relationship between the physical and digital world, demands a new and different approach of the relationships between these phenomena. As a result of the increasing number of connections, the process of organising, decision-making, and performing activities within and between organisations increasingly depends upon the ever-increasing quantities of information produced by and from the subjects and objects that are connected to each other in networks. The development of connections between hybrid systems can be regarded from the perspective of the system theory of Luhmann (1995).

When connections between systems and entities have been realised successfully, information will be exchanged and shared among objects and subjects in and between organisations. However, the incoming information does not become meaningful to the organisation until this information is given meaning within the receiving organisation. The process of assigning meaning to the incoming information in organisations is indicated by Weick as 'sensemaking' $(1979,1995)$. From this perspective of interoperability of information, we will, in this final part, discuss the system theory of Luhmann as well as the theory of 'sensemaking' by Weick. As previously described by van Lier (2009) and van Lier and Hardjono (2010;2011) Luhmann's systems theory is based on the principle of self-referential and autonomous systems. A system is self-referential when it is capable of forming elements that function as functional units, and when relations between these functional units and the system can be perceived as units and relations that were engendered by the system itself. The system thus continuously reproduces itself through the creation of functional units and their mutual relations which Luhmann (1995) calls autopoiesis. Self-production of elements enables self-referential and autonomous systems to set up relations with themselves and to differentiate these relations from relations with their environment.

\subsection{Double Contingency}

In order to be able to tackle the issue of how self-referential, autopoietic and autonomous systems can interact and communicate with one or several systems, it was for Luhmann (1995) necessary to shift the focus from the orientation of a single given actor to the consideration of two or more interacting actors as a system. According to van Lier (2009) Luhmann refers to this change using the theorem 'double contingency', which basically means that two random black boxes are connected through a random event and are looking to harmonise. Each 
black box assumes that the other black box has the same intentions. The black boxes attempt to influence each other on the basis of what they register, and can learn from each other on the basis of the acquired information.

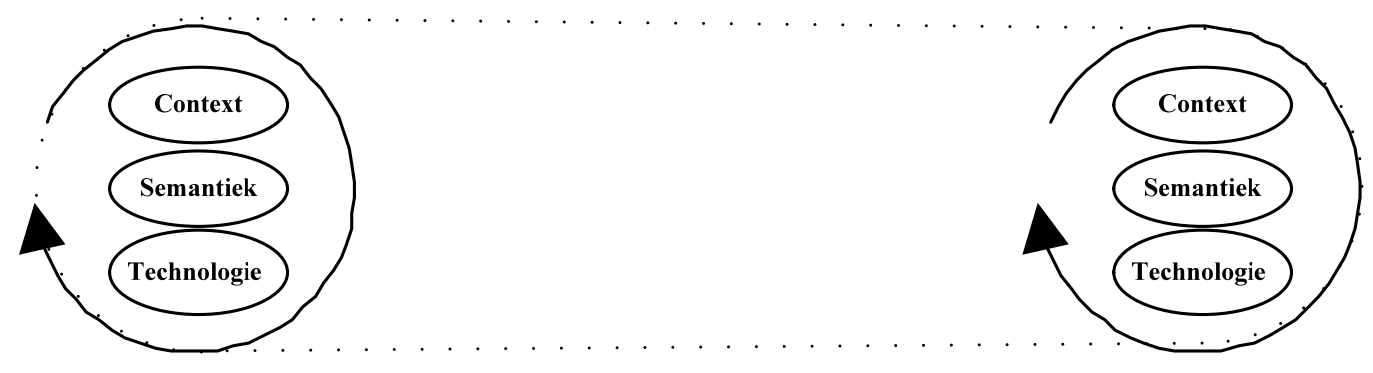

Figure 2. van Lier (2009) double contingency

\subsection{System and Environment}

According to van Lier (2009) and van Lier \& Hardjono (2010; 2011), the distinction between system and environment constitutes the central paradigm of systems theory. Luhmann (1995) adds to this central condition that information is only really information the moment it is more than an existing distinction between system and environment, it is information only if it instigates a change of state in the system he states. And the latter is in his eyes only the case when he, states: "the perception of a difference creates a difference in the system. Something was not known; then information arrives, namely that these, and none other, are the facts of matter" (2006:40). In other words the difference that is referred to here comes into being when perception of information actually leads to changes in the perceiving systems. Every perception, description and conceptualisation of a certain category requires a system reference, within which something can be considered part of a system or its environment.

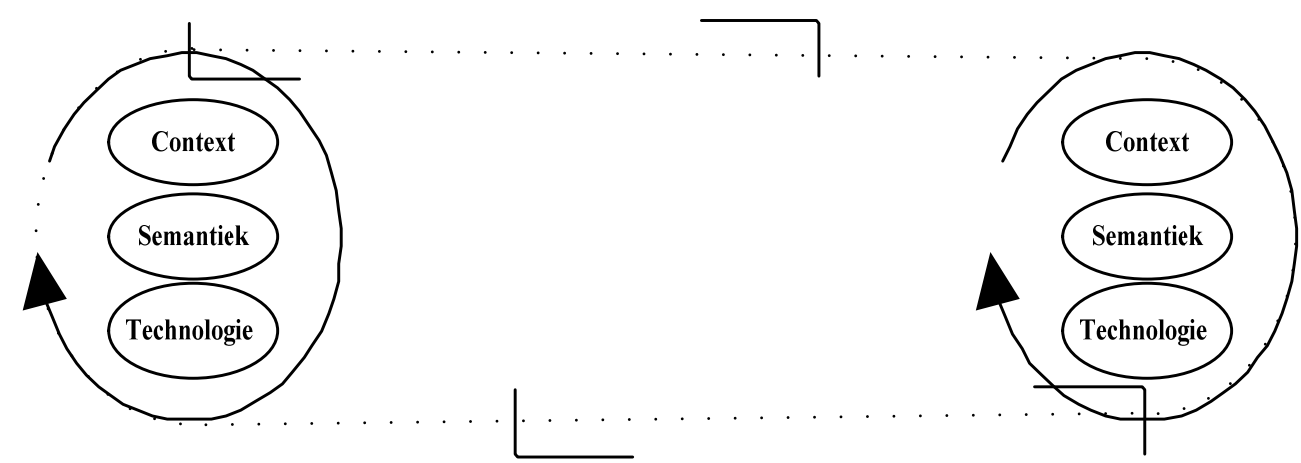

Figure 3. van Lier (2009) system and environment

\subsection{Communication and Action}

In the opinion of van Lier (2009) and van Lier and Hardjono (2010;2011) communication contains information and according to Luhmann: "is enriched with environmental meaning whenever this information comes from the environment; actions however are more easily determined as belonging to the system or not"(1995:180). If the system we depart from has the ability to understand this, this system will be able to discern another system in its environment and distinguish it from the environment they have in common. The relationship between the system and the environment has to be reproduced on a higher level of system complexity with increased possibilities and restrictions. Luhmann (1995) feels that communication is based too much on the principle of sending and receiving messages or information between senders and recipients as described by Shannon (1948). In his opinion, the metaphor of sending and receiving positions the essential part of communication within the action of sending, i.e.: 'the utterance' or the communicated message. According to Luhmann (1995) communication is more than just sending and receiving, with selective attention from both sides. He is convinced that a third part 
of the selection process consists of the concept 'understanding'. Luhmann (1995) ascertains that the understanding of communication contains a distinction between the informative value of the content and the reason why this content is uttered. Either side can be emphasised. The understanding process can focus more on the information itself or focus on the way the information is expressed. But this always depends on the fact that both facets are experienced as a selection, and therefore separated from each other. In other words: one needs to be able to accept that information as such is not understood, but that it requires separate decisions.

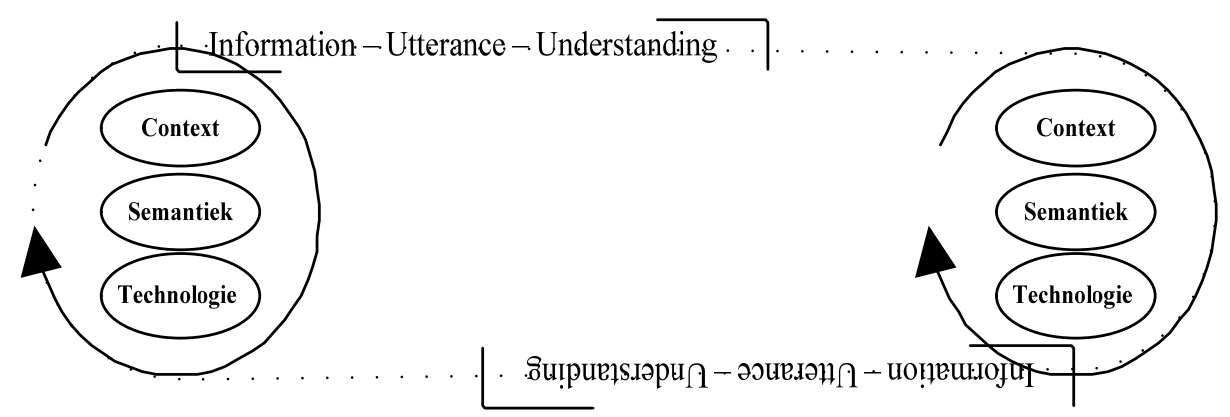

Figure4. van Lier (2009) communication and action

\subsection{Interpenetration}

As described by van Lier (2009) and van Lier \& Hardjono (2009;2010) the communicative unit can be rejected or received by the receiving system according to Luhmann (1995). When systems possess a reciprocal willingness and ability to accept the communicative unit, and grant communicative acts from other systems access to their system, a form of interpenetration comes about: "Interpenetrating systems converge in individual elements - that is they use the same ones - but they give each of them a different selectivity and connectivity, different past and futures." (1995:215). Luhmann uses the concept of 'interpenetration' to pinpoint the special way in which systems contribute to the shaping of the system within the environment of the system. Interpenetration is more than just a general relationship between system and environment, but rather an inter-system relationship between two systems that make up an environment for each other, and through which a system makes its own complexity available to build other systems. Interpenetration therefore only really occurs when these processes are evenly matched. As van Lier \& Hardjono $(2010 ; 2011)$ ascertains, the bringing about of connections between two or more systems ensures the evolutionary creation of a new and higher form of system formation. The new system formation consists of autonomous and self-referential systems that are in connection with each other. The concept of interpenetration does according to Luhmann (1995) not connect performance, but realises connections with which each system stabilises its internal complexity. Systems want to quickly have at their disposal any information from their environment that is new and relevant to them and be able to adequately apply this information within their own complexity. Therefore, new information has to be acceptable to the system and enable the system to assign 'Sinn' or meaning to the information. Only the way in which the information available is surveyed by systems makes information meaningful information.

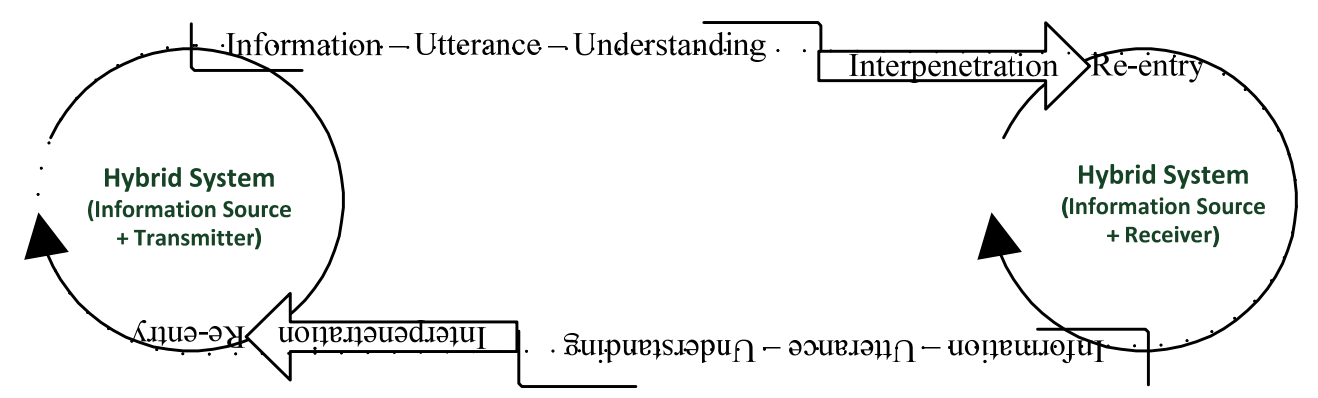

Figure 5. van Lier (2013) interoperability of information 


\subsection{Sensemaking}

The organisation as a social system operates and carries out activities on the basis of information as raw material according to van Lier (2011-2). How this information arrives or where it comes from is in his view not relevant to the organisation. The result of the processing of this information has many appearances and combinations. The connections in the process of information processing are put into the organisation according to Weick $(1979 ; 1995)$ in the form of nouns, which, in turn, form the basis for the information-processing process. This basis is mixed with other interests and activities, also present in and around the process, of the subjects and objects involved. As a result, real events in organisations are strongly dependent on the way in which connections in the process were or are realised, the direction from which these events are influenced, and the time it takes to take information through the available network of connections. Changes that arise from connections between the organisation as a system and its environment ensure what Weick $(1979 ; 1995)$ calls a meaningful environment. The incoming changes demand an active action from the organisation of assigning meaning (enactment) by subjects or objects. Many of the incoming changes are caused by the interpenetration of information from the environment. This incoming information forms the basic material for a process of sensemaking in organisations.

As van Lier (2011-2) describes the mutual influencing between subject and object is serving as a model for the relationship between 'enactment' and 'ecological change'. Such a mutual influencing is observed by Weick especially in organisations that strongly depend on technology and technological applications for the performance of their work and activities. They have to realise 'enactment' around and keeping in mind the possibilities and impossibilities of this technology. The strong connections with and dependencies on technology and technological applications are causing changes to the process of 'enactment' in organisations. However, Weick (1995) believes it would be going too far to argue that 'enactment' is reduced as the intensity of technology increases. According to him, such an argument would disregard the fact that these changes do not develop as a result of the technology in itself, but as a result of the information generated by this technology and the information that is increasingly processed in organisations with the help and intervention of technological applications. Technology is generating increasingly large quantities of raw data. This development is also making increasingly high demands of organisations to include this raw data in their own context, in such a way that this data can be processed into useful and manageable information.

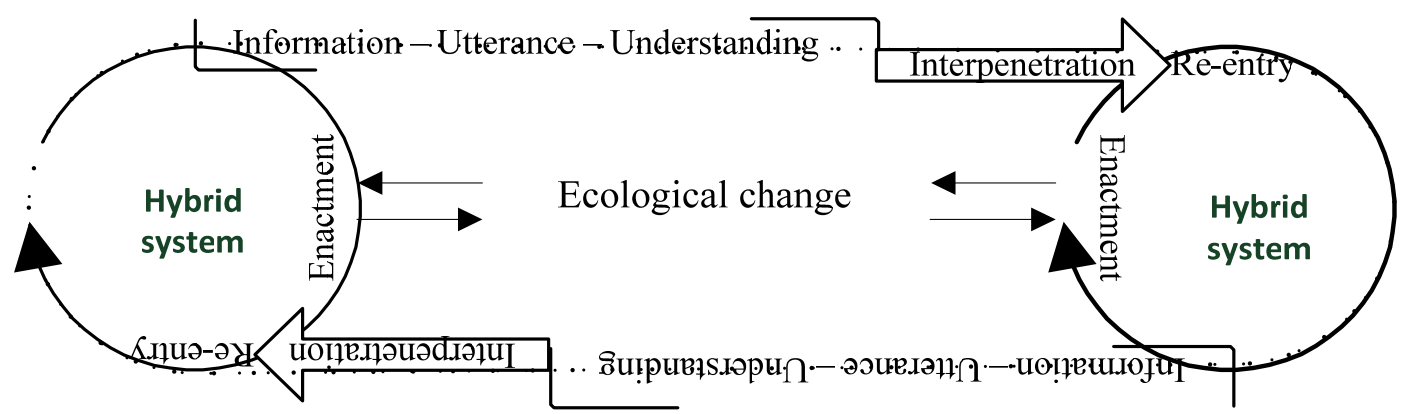

Figure 6. van Lier (2009) Interoperability of information and meaning

\section{Conclusions}

In the years ahead, more and more objects will be connected to the Internet. This way, the existing Internet, where information is currently predominantly exchanged and shared by people, will slowly but surely evolve into an Internet of Things. Within this Internet of Things, objects will not only communicate with each other, but also with people, resulting in random coalitions comprising objects and people. Communication between objects is also called machine2machine communication and takes place with the help of technological applications that are able to send and receive so-called 'messages'. As formulated in the theory of Shannon, the mere sending and receiving of 'messages', without any semantics or meaning, is not sufficient for people or organisations to be able to obtain meaningful information that enables them to act, produce or generate. Meaningful information does not develop until the sending and receiving of 'messages' is combined with an information source that is able to assign meaning to these 'messages'. This combination of information source and technical sender or receiver is called a hybrid system. Communication between random autonomous and hybrid systems is possible 
on the basis of interoperability of information. Complementary to the theory of Shannon, interoperability of information in this is based on the following concepts by Luhmann: double contingency, system and environment, communication and action, and interpenetration. The action of assigning meaning to new incoming information in hybrid systems - such as organizations - is based on the concept of enactment, taken from the theory of sensemaking by Weick. A cohesive whole of hybrid systems, based on interoperability of information such as the developing Internet of Things, comprising large numbers of active components that are mutually communicating, is very diverse according to form and possibilities. Such systems may also be designated as 'complex adaptive systems'. One of the most important characteristics of these 'complex adaptive systems', according to Holland (1995), is that: "the coherence and persistence of each system depend on extensive interactions, the aggregation of diverse elements, and adaptation or learning”. (1995:4). The connecting of objects and people in networks into an Internet of Things is creating a new cohesion between communication processes of subjects (human communication) and objects (machine2machine communication). This way, the combined communication processes will form a new ecosystem comprising interconnected and intercommunicating subjects and objects. According to Holland, such ecosystems are continuously: "in a state of flux and exhibit a wondrous panoply of interactions such as mutualism, parasitism, biological arms race and mimicry. Matter, energy and information are shunted around in complex cycles" (1995:3). In order to continue to be able to understand the developing Internet of Things as a 'complex adaptive system', we have to learn to better fathom and understand the development patterns that are present in it. Without understanding how these mutual patterns are being composed and how these are influencing us as human beings and organisations, we cannot understand how the Internet of Things as a whole is affecting and changing our daily activities and our perception of reality, both at home and in organisations.

\section{References}

Ashby, R.W. (1947). The nervous system as physical machine: With special reference to the origin of adaptive behavior. Mind new series, 56(221), 44-59. http://dx.doi.org/10.1093/mind/LVI.221.44

Ashby, R.W. (1954). Design for a brain. New York, John Wiley \& Sons.

Ashby, R.W. (1957). An introduction to Cybernetics (2nd ed.). London, Chapman \& Hall Ltd.

Ashby R.W. (1962). Principles of the self-organizing system. Classical papers E:CO special double issue, 6, 102-126.

Atzori, L., Iera, A., \& Morabito, G. (2010). The Internet of Things: A survey. Computer Networks, 54, 2787-2805. http://dx.doi.org/10.1016/j.comnet.2010.05.010

Bandyopadhyay, D., \& Sen, J. (2011). Internet of Things - Applications and challenges in technology and $\begin{array}{lllll}\text { standardization. } & \text { Wireless } & \text { Personal } & \text { Communications, } & 58,\end{array}$ http://dx.doi.org/10.1007/s11277-011-0288-5

Bateson, G. (1972). Steps to an ecology of mind. Chicago, The University of Chicago Press.

Berger, P., \& Luckmann, T. (1966). The social construction of reality. A treatise in the sociology of knowledge. New York, Penguin Books.

Clark, A. (2003). Natural-born cyborgs. Minds, technologies and the future of human intelligence. New York, Oxford University Press.

Cooper, R. (2005). Peripheral Vision: Relationality. Organization Studies, 26(11), 1689-1710. http://dx.doi.org/10.1177/0170840605056398

Holland, J. H. (1995). Hidden order. How adaptation builds hidden order. Basic books.

van Lier, B. (2009). Luhmann ontmoet 'the Matrix'; Uitwisselen en delen van informatie in Netcentrische omgevingen. (Luhmann meets 'the Matrix'; Exchanging and sharing information in network-centric environments.) Delft, Eburon.

van Lier, B. (2011, 2012). Connections, Information and Reality; Thinking about the Internet of Things. Journal of Systemics, Cybernetics and Informatics, 9(5), 91-97.

van Lier, B., \& Hardjono, T. W. (2010). Luhmann meets the Matrix. Exchanging and sharing information in network-centric environments. Journal of Systemics, Cybernetics and Informatics, 9(3), 68-72. 
van Lier, B., \& Hardjono, T. W. (2011). A system theoretical approach to interoperability of information Systemic Practice and Action research, 24(5), 479-497. http://dx.doi.org/10.1007/s11213-011-9197-5

Luhmann, N. (1995). Social Systems. Stanford, Stanford University Press.

Luhmann, N. (2006). System as difference. Organization, 13(1), 37-57. http://dx.doi.org/10.1177/1350508406059638

Ma, H. (2011). Internet of Things: Objectives and Scientific challenges. Journal of Computer Science and Technology, 6(6), 919-924. http://dx.doi.org/10.1007/s11390-011-1189-5

McKinney, E. H. Jr., \& Yoos, C. (2010). Information about information: A taxonomy of views. MIS Quarterly, 34(2), 329-344.

OECD. (2012). Machine-to-Machine communications: Connecting billions of devices. OECD Digital Economy Papers (No.192).

Rosenblueth, A., Wiener, N., \& Bigelow, J. (1943). Behavior, Purpose and Teleology. Philosophy of Science, 10, 18-24. http://dx.doi.org/10.1086/286788

Schrodinger, E. (1944). What is life? and Mind and Matter \& autobiographical sketches. Cambridge University Press.

Shannon, C. E. (1948). A mathematical theory of communication. The Bell System Technical Journal, 27, $379-423$.

Stonier T. (1996). Information as a basic property of the universe. BioSystems, 38, 135-140. http://dx.doi.org/10.1016/0303-2647(96)88368-7

Sundmaeker, H., Guillemin, P., Friess, P., \& Woelffle, S. (2010). Vision and Challenges for realising the Internet of Things, Publication office of the European Union.

Tribus, M., \& McIrvine, E. (1971). Energy and Information. Scientific American, 224, 179-184. http://dx.doi.org/10.1038/scientificamerican0971-179

Weaver, W. (1949). The Mathematics of Communication. Scientific American, 181, 11-15. http://dx.doi.org/10.1038/scientificamerican0749-11

Weick, K. E. (1995). Sensemaking in organizations. Thousand Oaks, Sage Publications.

Weick, K. E. (1979). The social psychology of organizing. New York, McGraw-Hill Inc.

Wiener, N. (1948). Cybernetics or control and communication in the animal and the machine. New York, The technology Press John Wiley \& Sons, INC.

Wilkinson, J. (1961). The concept of information and the unity of science. Philosophy of Science, 28(4), 406-413. http://dx.doi.org/10.1086/287826 